\title{
Investigation of Changes in the Fine Structure of Graphitizing Carbon Materials during Heat Treatment by X-Ray Diffraction Analysis
}

\author{
Vasiliy A. Tyumentsev, Alfiya G. Fazlitdinova \\ Condensed Matter Physics Department, Physics Faculty, Chelyabinsk State University, Chelyabinsk, Russia \\ Email: tyum@csu.ru
}

How to cite this paper: Tyumentsev, V.A. and Fazlitdinova, A.G. (2020) Investigation of Changes in the Fine Structure of Graphitizing Carbon Materials during Heat Treatment by X-Ray Diffraction Analysis. Journal of Materials Science and Chemical Engineering, 8, 11-20.

https://doi.org/10.4236/msce.2020.810002

Received: September 10, 2020

Accepted: October 16, 2020

Published: October 19, 2020

Copyright $\odot 2020$ by author(s) and Scientific Research Publishing Inc. This work is licensed under the Creative Commons Attribution International License (CC BY 4.0).

http://creativecommons.org/licenses/by/4.0/

\begin{abstract}
The properties of synthetic graphite materials, widely used in advanced fields, are determined by their structure, which is formed in the process of high-temperature $\left(\sim 2500^{\circ} \mathrm{C}\right)$ heat treatment. The fine structure of a graphitizing carbon material based on petroleum coke containing $1.3 \mathrm{wt} \% \mathrm{~S}$ at various stages of graphitization was studied by X-ray diffraction analysis. Some of the samples contained the addition of dispersed $\mathrm{Fe}_{2} \mathrm{O}_{3}$. It is shown that the heat-treated material in the range $1200^{\circ} \mathrm{C}-2600^{\circ} \mathrm{C}$ is heterogeneous, its component composition is determined by the processing temperature and the presence of $\mathrm{Fe}_{2} \mathrm{O}_{3}$ additive. The observed dependence of the component composition on the heat treatment temperature suggests that the process of graphitization of the carbon material, apparently, develops through a number of metastable states.
\end{abstract}

\section{Keywords}

Graphitization, X-Ray Diffraction Analysis, Microstructure, Coherent Scattering Regions

\section{Introduction}

Graphite materials, carbon fibers, and carbon-carbon composites are widely used in advanced areas that provide technical progress. The operational properties of these materials are largely determined by the crystal structure formed in the production process [1]-[7]. To diagnose changes in the structure of carbon materials at different stages of production, to study the effect of special additives, $\mathrm{X}$-ray diffraction analysis methods are widely used to determine the degree of graphitization, dispersed and phase composition, and texture parameters [3] [4] 
[5] [6] [7]. In particular, according to the data of X-ray diffraction studies (for example, in [7]), it was concluded that the interplanar distance decreases rather smoothly and the average size of the coherent scattering regions (CSR) increases with increasing graphitization temperature. At the same time, a number of studies have observed a stepwise change in the interplanar distance during heat treatment, neutron irradiation, or long-term mechanical dispersion [8]-[13]. It was assumed [8] [9] that metastable states with differing in the value of $\mathrm{d}_{002}$ can form in carbon materials. The formation of such metastable states causes the appearance of an asymmetry of the (002) and (004) diffraction peaks. In order to obtain additional information on the structural transformations of carbon material during graphitization, the authors of [4] [9] decomposed the profiles of the (002) and (004) asymmetric peak into two components and calculated the structural parameters of the separated phases. The study of the fine structure of carbon fibers (CF) obtained under various conditions was carried out in [14] [15] [16]. It is shown that the asymmetry of diffraction peak depends on the conditions of CF production. Using the program Origin, the authors decomposed the (002), (004) and (006) asymmetric diffraction peaks into the minimum number of symmetric described Gaussian or Voight functions. It turned out that the calculated values of the interplanar distances of the decomposition components are in good agreement with the data published in [8] [9]. The relationship between changes in the CF's fine structure and the conditions of production is traced. In this article, the method for analyzing the profile of the diffraction peak, tested in [14] [15] [16], was used to analyze the fine structure of a graphitizing carbon material heat-treated at temperatures from $1200^{\circ} \mathrm{C}$ to $2600^{\circ} \mathrm{C}$.

\section{Experimental}

$\mathrm{X}$-ray diffraction analysis was carried out using D8 ADVANCE diffractometer (filtered $\mathrm{CuKa}$ radiation, $40 \mathrm{kV}, 40 \mathrm{~mA}$ ). Powdered samples were scanned from 20 to 32 in $2 \theta$ range with 0.03 degree step interval and $2 \mathrm{sec} / \mathrm{step}$ counter-time, from 48 to 59 in $2 \theta$ range with 0.05 degree step interval and 4 sec/step counter-time). Sample rotation speed in the plane of self-focusing is $15 \mathrm{rps}$.

Samples of graphitizing carbon materials were made from a mixture of dispersed petroleum coke (sulfur content $1.3 \mathrm{wt} \%$ ) and $25 \%$ pitch, which were pressed in the forms of cylinders and carbonized at $900^{\circ} \mathrm{C}$ for 3 hours. Some of the samples contained the addition of dispersed $\mathrm{Fe}_{2} \mathrm{O}_{3}$ in an amount of $0.75 \mathrm{wt} \%$. High-temperature treatment in the range $1200^{\circ} \mathrm{C}-2600^{\circ} \mathrm{C}$ was carried out for 3 hours, the rate of temperature rises to a predetermined was 300 degrees per hour. The profiles of the (002) and (004) asymmetric diffraction peaks of carbon materials were analyzed using Origin. For this, the experimentally obtained asymmetric peak was decomposed into components whose profile is described by the Voigt function. The minimum number of decomposition components was determined by the coincidence of the profile of the total peak of the compo- 
nents with the experimentally obtained peak (the coefficient of determination $\mathrm{R}^{2}$ is within $0.9963-0.9998$ ). The interplanar distance $d_{002}$ and the average size of the CSR $\mathrm{L}_{002}$ of the selected components were calculated from the center of gravity and the integral width of the peak (in the Scherrer equation, the constant $\mathrm{k}$ was taken to be 1). The quantitative ratio of the components in the studied carbon materials was estimated in proportion to the ratio of the peak areas of the decomposition components.

\section{Results and Discussion}

The profiles of the (002) and (004) diffraction peaks of the samples of the studied graphitizing carbon, which heat-treated at $1200^{\circ} \mathrm{C}-2600^{\circ} \mathrm{C}$, are usually not symmetric, Figure 1, Figure 2. This may be due to the simultaneous presence of metastable carbon phases differing in the value of the interplanar distance. According to the literature [8] [9], up to six metastable states can be realized in a carbon material, which correspond to the values of the interplanar distance: $\mathrm{d}^{1}{ }_{002}$ $=0.335, \mathrm{~d}^{2}{ }_{002}=0.337, \mathrm{~d}^{3}{ }_{002}=0.340, \mathrm{~d}^{4}{ }_{002}=0.3425, \mathrm{~d}^{5}{ }_{002}=0.3440$ and $\mathrm{d}^{6}{ }_{002}=$ $0.355 / 0.368 \mathrm{~nm}$. Let us designate the state (components) that determine these values of interplanar distances, as $\mathrm{C}_{1}, \mathrm{C}_{2}, \ldots \mathrm{C}_{6}$.

The profile of the (002) peak of a carbon material heat-treated at $1200^{\circ} \mathrm{C}$ can be confidently decomposed into two components, which we denote as $\mathrm{C}_{5}$ and $\mathrm{C}_{6}$ $\left(\mathrm{d}^{5}{ }_{002} \sim 0.344\right.$ and $\left.\mathrm{d}^{6}{ }_{002} \sim 0.359 \mathrm{~nm}\right)$, coefficient $\mathrm{R}^{2}=0.9977$, Table 1 . An increase in
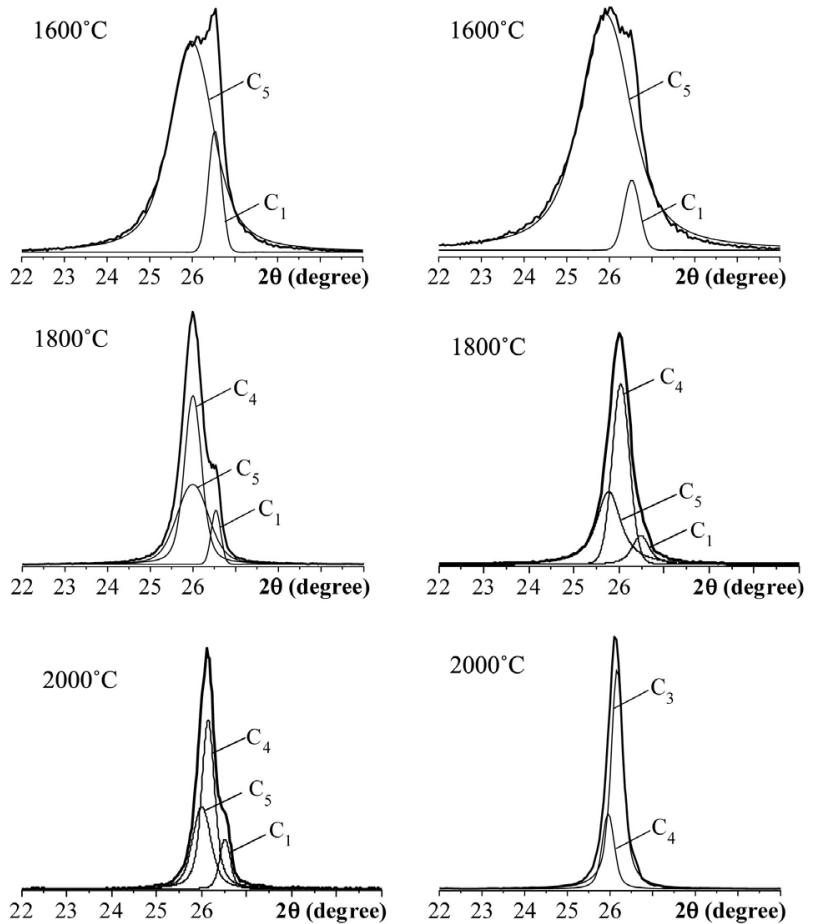

(a)

(b)

Figure 1. The profiles of (002) diffraction peaks of carbon material, heat-treated at $1600^{\circ} \mathrm{C}, 1800^{\circ} \mathrm{C}$, and $2000^{\circ} \mathrm{C}$ without additive (a) and containing an additive of dispersed $\mathrm{Fe}_{2} \mathrm{O}_{3}(\mathrm{~b})$. 

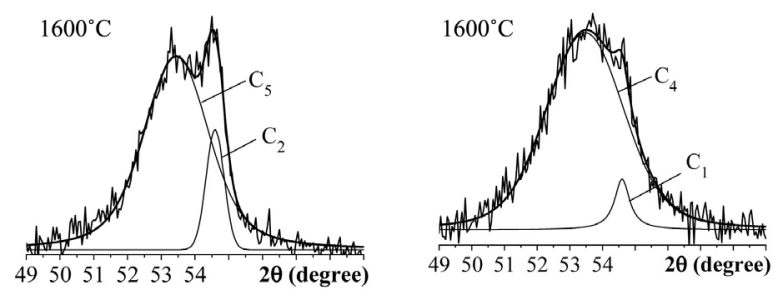

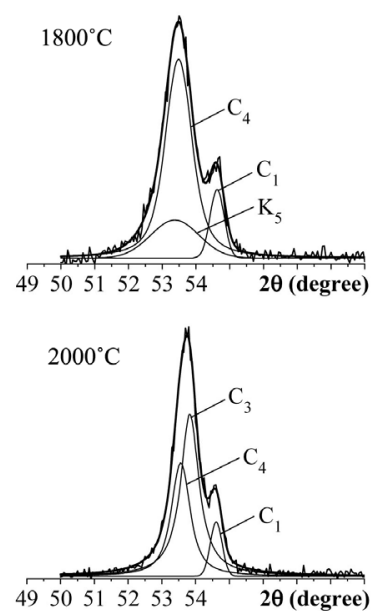

(a)
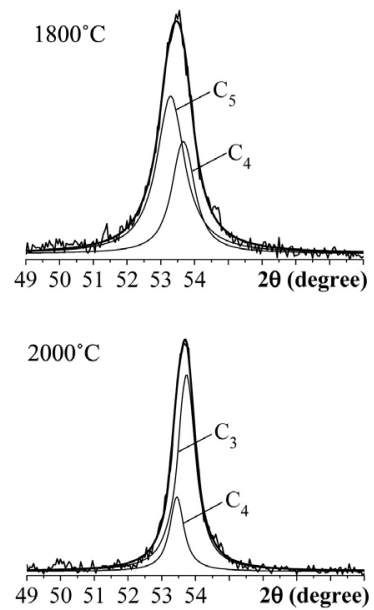

(b)

Figure 2. Profiles of (004) diffraction peak samples of carbon material heat-treated at $1600^{\circ} \mathrm{C}, 1800^{\circ} \mathrm{C}$ and $2000^{\circ} \mathrm{C}$ without additive (a) and containing addition of dispersed $\mathrm{Fe}_{2} \mathrm{O}_{3}(\mathrm{~b})$.

Table 1. Component composition and structure parameters of the carbon material calculated from the results of the analysis of the (002) diffraction peak.

\begin{tabular}{|c|c|c|c|c|c|}
\hline No. Sample & Temperature, ${ }^{\circ} \mathrm{C}$ & Components & $\mathrm{d}_{002}, \AA$ & $\mathrm{L}_{002}, \mathrm{~nm}$ & Content component, $\%$ \\
\hline \multirow{2}{*}{1} & \multirow{2}{*}{1200} & $\mathrm{C}_{5}$ & 3442 & 4 & 60 \\
\hline & & $\mathrm{C}_{6}$ & 3586 & 2 & 40 \\
\hline \multirow{2}{*}{2} & \multirow{2}{*}{1400} & $\mathrm{C}_{5}$ & 3433 & 6 & 80 \\
\hline & & $\mathrm{C}_{6}$ & 3571 & 4 & 20 \\
\hline \multirow{2}{*}{3} & \multirow{2}{*}{1600} & $\mathrm{C}_{1}$ & 3360 & 25 & 15 \\
\hline & & $\mathrm{C}_{5}$ & 3431 & 8 & 85 \\
\hline \multirow{3}{*}{4} & \multirow{3}{*}{1800} & $\mathrm{C}_{1}$ & 3360 & 30 & 10 \\
\hline & & $\mathrm{C}_{4}$ & 3426 & 17 & 60 \\
\hline & & $\mathrm{C}_{5}$ & 3443 & 10 & 30 \\
\hline \multirow{3}{*}{5} & \multirow{3}{*}{2000} & $\mathrm{C}_{1}$ & 3360 & 29 & 10 \\
\hline & & $\mathrm{C}_{4}$ & 3427 & 20 & 60 \\
\hline & & $\mathrm{C}_{5}$ & 3440 & 18 & 30 \\
\hline \multirow{2}{*}{6} & \multirow{2}{*}{2200} & $\mathrm{C}_{2}$ & 3378 & 24 & 30 \\
\hline & & $\mathrm{C}_{3}$ & 3395 & 21 & 70 \\
\hline \multirow{2}{*}{7} & \multirow{2}{*}{2400} & $\mathrm{C}_{2}$ & 3371 & 26 & 35 \\
\hline & & $\mathrm{C}_{3}$ & 3389 & 20 & 65 \\
\hline \multirow{2}{*}{8} & \multirow{2}{*}{2600} & $\mathrm{C}_{2}$ & 3370 & 29 & 40 \\
\hline & & $\mathrm{C}_{3}$ & 3387 & 20 & 60 \\
\hline
\end{tabular}


the processing temperature to $1400^{\circ} \mathrm{C}$ did not lead to a change in the component composition of the material, however, the sizes of CSR $\mathrm{L}_{002}$ increased to $\sim 6$ and $\sim 4 \mathrm{~nm}$, respectively. During heat treatment at $1600^{\circ} \mathrm{C}$, rather large crystals of a new phase were formed in the carbon material, the interplanar distance and CSR sizes of which were $\mathrm{d}_{002} \sim 0.336 \mathrm{~nm}, \mathrm{~L}_{002} \sim 25 \mathrm{~nm}$, the amount of $\mathrm{C}_{1}$ component $\sim 15 \%$. The second component of the decomposition of the asymmetric diffraction peak corresponds to $\mathrm{C}_{5}$, the CSR size of which is $\mathrm{L}_{002} \sim 8 \mathrm{~nm}$.

The (002) asymmetric diffraction peak of samples No. 4 and No. 5, heat-treated at $1800^{\circ} \mathrm{C}$ and $2000^{\circ} \mathrm{C}$, can be presented as a sum of three symmetric peaks (coefficient $\mathrm{R}^{2}$ in the expansion of (002) peak is 0.9997 and 0.9989 , respectively). From the calculations given in Table 1, it follows that these samples contain components $\mathrm{C}_{1}, \mathrm{C}_{4}$ and $\mathrm{C}_{5}$.

The asymmetry of the (002) diffraction peak is also observed in the diffraction patterns of the samples heat-treated at $2200^{\circ} \mathrm{C}, 2400^{\circ} \mathrm{C}$, and $2600^{\circ} \mathrm{C}$. However, these peaks are confidently decomposed into only two components (the $\mathrm{R}^{2}$ coefficient is $0.9978,0.9990$, and 0.9994 , respectively). The interplanar distances calculated from the results of the expansion of the (002) peak correspond to the components $\mathrm{C}_{2}$ and $\mathrm{C}_{3}$. As the processing temperature increases, an increase in the CSR size and the amount of the $\mathrm{C}_{2}$ component is observed.

Figure 1(b), Figure 2(b) show the profiles of the (002) and (004) diffraction peaks of the samples of carbon material containing the addition of dispersed $\mathrm{Fe}_{2} \mathrm{O}_{3}$. It can be seen that the asymmetry of the peaks of the samples subjected to heat treatment at $1600^{\circ} \mathrm{C}, 1800^{\circ} \mathrm{C}$, and $2000^{\circ} \mathrm{C}$ is less pronounced. The results of the decomposition of the (002) asymmetric diffraction peak into components and the calculation of the parameters of the structure of metastable states are given in Table 2. In the presence of an addition of iron oxide, the components $\mathrm{C}_{3}, \mathrm{C}_{6}\left(\mathrm{R}^{2}=0.9970\right)$ and $\mathrm{C}_{4}, \mathrm{C}_{5}\left(\mathrm{R}^{2}=0.9983\right)$ are registered in the sample that heat treated at $1200^{\circ} \mathrm{C}$ and $1400^{\circ} \mathrm{C}$, respectively.

The component composition of the samples without and with the addition of $\mathrm{Fe}_{2} \mathrm{O}_{3}$ after heat treatment at $1600^{\circ} \mathrm{C}$ and $1800^{\circ} \mathrm{C}$ is the same, however, the CSR size and the amount of component $\mathrm{C}_{1}$ in the second case turned out to be noticeably smaller, Table 2 . The (002) diffraction peak of the sample heat treated at $2000^{\circ} \mathrm{C}$ decomposes into two components $\mathrm{C}_{3}$ and $\mathrm{C}_{4}$. In this case, it was not possible to isolate the component $\mathrm{C}_{1}$, which is confidently recorded in sample No. 5. Sample No. 14 turned out to be one-component, the (002) diffraction peak is symmetric and fairly well approximated by the Voigt function, the coefficient $R^{2}$ is 0.9963 .

The peak of samples No. 15 and No. 16 are confidently decomposed into two components (the coefficient $\mathrm{R}^{2}$ is equal to 0.9994 and 0.9996 , respectively). The interplanar distances calculated from the results of the expansion of the peak correspond to the components $\mathrm{C}_{2}$ and $\mathrm{C}_{3}$. The CSR sizes formed in the carbon material in the presence of $\mathrm{Fe}_{2} \mathrm{O}_{3}$ additive at $2400^{\circ} \mathrm{C}$ and $2600^{\circ} \mathrm{C}$ turned out to be much larger than those of samples No. 7 and No. 8. 
Table 2. Component composition and structure parameters of the carbon material containing the addition of $0.75 \mathrm{wt} \% \mathrm{Fe}_{2} \mathrm{O}_{3}$, calculated from the results of the analysis of the (002) diffraction peak.

\begin{tabular}{|c|c|c|c|c|c|}
\hline No. Sample & Temperature, ${ }^{\circ} \mathrm{C}$ & Components & $\mathrm{d}_{002}, \AA$ & $\mathrm{L}_{002}, \mathrm{~nm}$ & Content component, \% \\
\hline \multirow[b]{2}{*}{9} & \multirow[b]{2}{*}{1200} & $\mathrm{C}_{3}$ & 3.408 & 6 & 30 \\
\hline & & $\mathrm{C}_{6}$ & 3.512 & 3 & 70 \\
\hline \multirow{2}{*}{10} & \multirow{2}{*}{1400} & $\mathrm{C}_{4}$ & 3.420 & 8 & 60 \\
\hline & & $\mathrm{C}_{5}$ & 3.464 & 4 & 40 \\
\hline \multirow[b]{2}{*}{11} & \multirow[b]{2}{*}{1600} & $\mathrm{C}_{1}$ & 3.362 & 18 & 10 \\
\hline & & $\mathrm{C}_{5}$ & 3.443 & 7 & 90 \\
\hline \multirow{3}{*}{12} & \multirow{3}{*}{1800} & $\mathrm{C}_{1}$ & 3.360 & 20 & 5 \\
\hline & & $\mathrm{C}_{4}$ & 3.420 & 18 & 60 \\
\hline & & $\mathrm{C}_{5}$ & 3.435 & 15 & 35 \\
\hline \multirow{2}{*}{13} & \multirow[b]{2}{*}{2000} & $\mathrm{C}_{3}$ & 3.405 & 26 & 10 \\
\hline & & $\mathrm{C}_{4}$ & 3.423 & 21 & 30 \\
\hline 14 & 2200 & $\mathrm{C}_{3}$ & 3.394 & 22 & 100 \\
\hline \multirow{2}{*}{15} & \multirow{2}{*}{2400} & $\mathrm{C}_{2}$ & 3.372 & 35 & 40 \\
\hline & & $\mathrm{C}_{3}$ & 3.389 & 24 & 60 \\
\hline \multirow{2}{*}{16} & \multirow{2}{*}{2600} & $\mathrm{C}_{2}$ & 3.372 & 37 & 40 \\
\hline & & $\mathrm{C}_{3}$ & 3.388 & 24 & 60 \\
\hline
\end{tabular}

The results of the decomposition of the (004) diffraction peak of the carbon material into components and the calculation of the structural parameters mainly correlate with those described above (Table 3, Table 4).

In some cases, multiple analysis of the profile of the (002) diffraction peak of the same sample received decomposition components, the center of gravity and integral width of which practically did not change, but the ratio of the components differed significantly. In this case, we were guided by the choice of the decomposition variant in which the $\mathrm{R}^{2}$ value was the highest.

The clearly observed experimentally coexistence of the graphite phase (component $\mathrm{C}_{1}$ ) and the ultradispersed carbon matrix in the material heat-treated at $1600^{\circ} \mathrm{C}-1800^{\circ} \mathrm{C}$ is apparently due to local stimulation of graphitization in the process of active desulfurization of high-sulfur coke [17]. The removed sulfur can form a compound based on carbon and sulfur, in the presence of which the local recrystallization of the carbon material develops similarly to that with the addition of carbide-forming additives ( $\mathrm{Fe}, \mathrm{Gr}, \mathrm{Ni}$, etc.).

The addition of dispersed $\mathrm{Fe}_{2} \mathrm{O}_{3}$ had a significant effect on the change in the fine structure of high-sulfur carbon material during graphitization. Already at temperatures of $1200^{\circ} \mathrm{C}$ and $1400^{\circ} \mathrm{C}$, the recrystallization of the material is activated, new components $\mathrm{C}_{3}$ and $\mathrm{C}_{4}$ appear. In the temperature range of active desulfurization $\left(1600^{\circ} \mathrm{C}-1800^{\circ} \mathrm{C}\right)$, apparently, the interaction of sulfur and iron occurs, and iron sulfide is formed [18]. This process limits the catalytic effect of 
Table 3. Component composition and structure parameters of carbon material calculated from the results of the analysis of the (004) diffraction peak.

\begin{tabular}{|c|c|c|c|c|}
\hline No. Sample & Temperature, ${ }^{\circ} \mathrm{C}$ & Components & $\mathrm{d}_{002}, \AA$ & $\mathrm{L}_{002}, \mathrm{~nm}$ \\
\hline \multirow[b]{2}{*}{2} & \multirow[b]{2}{*}{1400} & $\mathrm{C}_{3}$ & 3.340 & 5 \\
\hline & & $\mathrm{C}_{5}$ & 3465 & \\
\hline \multirow{3}{*}{3} & \multirow{3}{*}{1600} & $\mathrm{C}_{2}$ & 3.367 & 11 \\
\hline & & & & \\
\hline & & $\mathrm{C}_{5}$ & 3.440 & 5 \\
\hline \multirow{3}{*}{4} & \multirow{3}{*}{1800} & $\mathrm{C}_{1}$ & 3.361 & 18 \\
\hline & & $\mathrm{C}_{4}$ & 3.418 & 12 \\
\hline & & $\mathrm{C}_{5}$ & 3.435 & 9 \\
\hline \multirow{3}{*}{5} & \multirow{3}{*}{2000} & $\mathrm{C}_{1}$ & 3.362 & 22 \\
\hline & & $\mathrm{C}_{3}$ & 3.409 & 14 \\
\hline & & $\mathrm{C}_{4}$ & 3.428 & 12 \\
\hline \multirow{3}{*}{6} & \multirow{3}{*}{2200} & $\mathrm{C}_{1}$ & 3.360 & 28 \\
\hline & & & & \\
\hline & & $\mathrm{C}_{3}$ & 3.394 & 13 \\
\hline \multirow[b]{2}{*}{7} & \multirow[b]{2}{*}{2400} & $\mathrm{C}_{2}$ & 3.367 & 16 \\
\hline & & $\mathrm{C}_{3}$ & 3.387 & 15 \\
\hline \multirow[b]{2}{*}{8} & \multirow[b]{2}{*}{2600} & $\mathrm{C}_{2}$ & 3.373 & 15 \\
\hline & & $\mathrm{C}_{3}$ & 3.386 & 10 \\
\hline
\end{tabular}

Table 4. Component composition and structure parameters of the carbon material containing the addition of $0.75 \mathrm{wt} \% \mathrm{Fe}_{2} \mathrm{O}_{3}$, calculated from the results of the analysis of the (004) diffraction peak.

\begin{tabular}{|c|c|c|c|c|}
\hline No. Sample & Temperature, ${ }^{\circ} \mathrm{C}$ & Components & $\mathrm{d}_{002}, \AA$ & $\mathrm{L}_{002}, \mathrm{~nm}$ \\
\hline \multirow[b]{2}{*}{10} & \multirow[b]{2}{*}{1400} & $\mathrm{C}_{3}$ & 3.389 & 6 \\
\hline & & $\mathrm{C}_{5}$ & 3.447 & \\
\hline \multirow{3}{*}{11} & \multirow{3}{*}{1600} & $\mathrm{C}_{1}$ & 3.359 & 22 \\
\hline & & & & \\
\hline & & $\mathrm{C}_{4}$ & 3.427 & 3 \\
\hline \multirow{3}{*}{12} & \multirow{3}{*}{1800} & $\mathrm{C}_{4}$ & 3.419 & 11 \\
\hline & & & & \\
\hline & & $\mathrm{C}_{5}$ & 3.439 & 8 \\
\hline \multirow[b]{2}{*}{13} & \multirow[b]{2}{*}{2000} & $\mathrm{C}_{3}$ & 3.409 & 17 \\
\hline & & $\mathrm{C}_{4}$ & 3.425 & 16 \\
\hline 14 & 2200 & $\mathrm{C}_{3}$ & 3.397 & 13 \\
\hline \multirow[b]{2}{*}{15} & \multirow[b]{2}{*}{2400} & $\mathrm{C}_{2}$ & 3.378 & 18 \\
\hline & & $\mathrm{C}_{3}$ & 3.393 & 13 \\
\hline \multirow{3}{*}{16} & \multirow{3}{*}{2600} & $\mathrm{C}_{2}$ & 3.375 & 20 \\
\hline & & & & \\
\hline & & $\mathrm{C}_{3}$ & 3.391 & 15 \\
\hline
\end{tabular}


sulfur, the amount of $\mathrm{C}_{1}$ component is significantly reduced. After heat treatment at $2000^{\circ} \mathrm{C}$, the contribution of the $\mathrm{C}_{1}$ component to the profile of the (002) and (004) diffraction peaks could not be distinguished. It should also be noted that in the presence of the $\mathrm{Fe}_{2} \mathrm{O}_{3}$ additive, an increase in the average CSR's size of the components formed in the carbon material under study at processing temperatures of $2200^{\circ} \mathrm{C}-2600^{\circ} \mathrm{C}$ is observed.

Thus, the analysis of the profile of the (002) and (004) diffraction peaks makes it possible to reveal the fine structure of the carbon material at various stages of the transition to graphite. It is shown that during heat treatment metastable states can be realized in a carbon material, the interplanar distance of which is in good agreement with those given in [8] [9]. It should be noted that, when analyzing the profiles of the (002) and (004) diffraction peaks, formed by the CSR of carbon fibers [14] [15], an unambiguous decomposition into components occurs. When analyzing the profiles of diffraction peaks of some samples of the studied graphitizing materials, as noted above, there can be several variants of decomposition. Apparently, this is due to the fact that the composition of the studied material includes high-sulfur petroleum coke and pitch coke formed during pitch carbonization. The graphitization processes in these carbon materials differ, which leads to the formation of a more complex profile of the (002) and (004) diffraction peaks.

\section{Conclusions}

The asymmetry of the (002) and (004) diffraction peaks of the carbon material at different stages of the transition to polycrystalline graphite is due to the superposition of closely spaced diffraction peaks of coherent scattering regions, which differ in the values of $\mathrm{d}_{002}$ and $\mathrm{L}_{002}$, indicates a significant inhomogeneity of the material in terms of dispersed and phase composition.

An analysis of the profile of the most intense asymmetric (002) diffraction peak of a carbon material makes it possible to obtain new data on its fine structure, to establish the relationship between the preparation modes and its fine structure.

In the process of high-temperature processing, recrystallization of the carbon material develops, accompanied by the formation of metastable states, the structural parameters of which depend on the processing temperature. The heterogeneous structure suggests that the transition of the carbon material to a more equilibrium state, apparently, develops through a number of metastable states.

The appearance at sufficiently low temperatures of the graphite phase (components $\mathrm{C}_{1}$ ) in the ultradispersed carbon matrix is apparently due to the local stimulation of graphitization during the active desulfurization of high-sulfur coke. The addition of iron significantly inhibits this process.

\section{Conflicts of Interest}

The authors declare no conflicts of interest regarding the publication of this paper. 


\section{References}

[1] Feret, F.R. (1998) Determination of the Crystallinity of Calcined and Graphitic Cokes by X-Ray Diffraction. Analyst, 123, 595-600.

https://doi.org/10.1039/A707845E

[2] Parshant, K. and Srivastava, V.K. (2016) A Review on Wear and Friction Performance of Carbon-Carbon Composites at High Temperature. International Journal of Applied Ceramic Technology, 13, 702-710. https://doi.org/10.1111/ijac.12538

[3] Wang, M. and Bian, W. (2020) The Relationship between the Mechanical Properties and Microstructures of Carbon Fibers. New Carbon Materials, 35, 42-49. https://doi.org/10.1016/S1872-5805(20)60474-7

[4] Gubernat, M., Lis, T., Tomala, J., Kawala, J., Fraczek-Szczypta, A. and Blazewicz, S. (2017) Study of the Carbonization and Graphitization of Coal Tar Pitch Modified with SiC Nanoparticles. Journal of Nanomaterials, 2017, Article ID: 6578928. https://doi.org/10.1155/2017/6578928

[5] Zhang, Z. and Wang, Q. (2017) The New Method of XRD Measurement of the Degree of Disorder for Anode Coke Material. Crystals, 7, 1-10. https://doi.org/10.3390/cryst7010005

[6] Barnakov, Ch.N., Khokhlova, G.P., Popova, A.N., Sozinov, S.A. and Ismagilov, Z.R. (2015) XRD Characterization of the Structure of Graphites and Carbon Materials Obtained by the Low-Temperature Graphitization of Coal Tar Pitch. Eurasian Chemico-Technological Journal, 17, 87-93. https://doi.org/10.18321/ectj198

[7] Zhao, J., Yang, L., Li, F., Yu, R. and Jin, C. (2009) Structural Evolution in the Graphitization Process of Activated Carbon by High-Pressure Sintering. Carbon, 47, 744-751. https://doi.org/10.1016/j.carbon.2008.11.006

[8] Lachter, J. and Bragg, R.M. (1986) Interstitials in Graphite and Disordered Carbons. Physical Review B, 33, 8903-8905. https://doi.org/10.1103/PhysRevB.33.8903

[9] Aladekomo, J.B. and Bragg, R.H. (1990) Structural Transformations Induced in Graphite by Grinding: Analysis of 002 X-Ray Diffraction Line Profiles. Carbon, 28, 897-906. https://doi.org/10.1016/0008-6223(90)90338-Y

[10] Ong, T.S. and Yang, H. (2000) Effect of Atmosphere on the Mechanical Milling of Natural Graphite. Carbon, 38, 2077-2085.

https://doi.org/10.1016/S0008-6223(00)00064-6

[11] Salver-Dismaa, F., Tarascona, J.-M., Clinardb, C. and Rouzaudb, J.-N. (1999) Transmission Electron Microscopy Studies on Carbon Materials Prepared by Mechanical Milling. Carbon, 37, 1941-1959. https://doi.org/10.1016/S0008-6223(99)00059-7

[12] Tadjani, M., Lechter, J., Kabret, T.S. and Bragg, R.H. (1986) Structural Disorder Induced in Graphite by Grinding. Carbon, 24, 447-449. https://doi.org/10.1016/0008-6223(86)90266-6

[13] Kawamura, K. and Bragg, R.H. (1986) Graphitization of Pitch Coke: Changes in Mean Interlayer Spacing, Strain and Weight. Carbon, 24, 301-309.

https://doi.org/10.1016/0008-6223(86)90231-9

[14] Tuymentsev, V.A. and Fazlitdinova, A.G. (2016) Relation between the Synthesis Conditions and the Fine Structure of Fiber Carbon. Technical Physics, 61, 380-387. https://doi.org/10.1134/S106378421603021X

[15] Tyumentsev, V.A., Fazlitdinova, A.G. and Podkopaev, S.A. (2019) Effect of Temperature of Thermomechanical Processing on the Heterogeneous Structure of Carbon Fiber. Technical Physics, 64, 1767-1773. https://doi.org/10.1134/S1063784219120259 
[16] Tyumentsev, V.A. and Fazlitdinova, A.G. (2019) Study of the Structure of Fibrous Carbon Materials Using X-Ray Diffractometry. Industrial Laboratory. Diagnostics of Materials, 85, 31-36. https://doi.org/10.26896/1028-6861-2019-85-11-31-36

[17] Tyumentsev, V.A., Belenkov, E.A., Shveikin, G.P. and Podkopaev, S.A. (1998) The Effects of Sulphur and Other Impurities on Carbon-Graphite Transition. Carbon, 36, 845-853. https://doi.org/10.1016/S0008-6223(97)00143-7

[18] Sugimoto, J., Derbyshire, F.J. and Scaroni, A.W. (1985) The Effect of Sulfur Evolution on the Properties of High-Temperature Carbons-II. The Addition of $\mathrm{Fe}_{2} \mathrm{O}_{3}$. Carbon, 23, 417-421. https://doi.org/10.1016/0008-6223(85)90035-1 